\title{
Education for development under the skies of Chile
}

\author{
Cecilia Scorza ${ }^{1,2}$ and Olaf Fischer ${ }^{2}$ \\ ${ }^{1}$ Heidelberg University ${ }^{2}$ House of Astronomy
}

\begin{abstract}
We report on an educational program initiated in Chile in the year 2010 on the frame of an excellence research and graduate exchange program between the University of Heidelberg and the Pontfica Catlica University in Chile, funded by the German International Exchange Office (DAAD).
\end{abstract}

The idea of accomplishing the excellence research initiative with educational activities for the Chilean schools relies on the large amount of observations carried out in Chile, the coming future observatories (e.g. ELT) and the heritage of the IYA 2009 which all together have produced a great impact on the Chilean society. The interest for astronomy education has enormously increased. As a consequence, the educational ministry in Chile has recognized the educational potential of astronomy in stimulating interest in natural, engineering and technical careers, and has introduced the new school subject "The Earth and the Universe" at all school levels.

The school subject spirals up through all levels connecting the contents of several school subjects on the frame of astronomical contexts. This has produced a huge demand of educational materials and teacher trainings in Chile because the schools have an open curricula, and teachers lack a background knowledge on astronomy.

Via the cooperation between the Heidelberg University and the House of Astronomy a first visit of the authors to Chile took place in November 2010. During that opportunity a meeting with authorities of the universities and observatories located in Chile, interested in supporting the educational activities, took place. Directors, professors and PR-experts from ESO, Cerro Tololo, Universidad Catlica, Universidad Pedagogica and Center for Latin America exchanged their ideas. Two teacher trainings ware offered in Santiago at the Planetario de Santiago de Chile and vists to Cerro Tololo in la Serena and schools in Antofagasta near to Paranal were carried out.

In order to support the better qualification of teachers in astronomy, two Chilean teachers were invited for a working stay of three weeks at the House of Astronomy. With our support the teachers Maria Paz Cornejo and Patricio Castro gained insights into the didactical materials developed at the HoA on the frame of the "Science into School" project (WIS). The aim of the WIS-program is to bring actual contents of modern astronomy research into the classroom. In doing so the gaps of activities in the program "The Earth and the Universe" were also identified and concrete ideas for new materials discussed. Among them arose the idea of developing materials related to the Mars exploration given the similarity between the Atacama desert and Mars landscapes. Once back to Chile both teachers implemented the activities at their schools and sent within four weeks a very positive report.

A second visit has been planned in January 2013 with the aim to make available the educational activities to other interested universities and schools located near the big telescopes. In several of these cities and small towns there is a considerable amount of disadvantaged children. Eight teacher trainings will be offered in Santiago, in San 
Pedro de Atacama with educational materials related to ALMA and with support of the ESO and the Associated Universities Inc. (AUI), and in Antofagasta and Valdivia (in collaboration with the program government program "Explora"). During these trainings materials related to ALMA and the VISTA-Camera at the VLT (ESO) will be made accessible to the teachers. A meeting in Santiago will bring together all interested parties with the educational ministry. In doing so we hope that pupils of the high schools living inside and outside Santiago get in touch via inquiry based activities with astronomy research made by Chilean astronomers using the best telescopes of the World. 